\title{
Literacy Acquisition in Indian Students: A Descriptive Study of Reading Achievement in One English Medium School
}

\author{
David D. Paige ${ }^{1, *}$, Victoria Spagnoli ${ }^{2} \&$ Holly Wood $^{2}$ \\ ${ }^{1}$ Annsley Frazier Thornton School of Education, Bellarmine University, Louisville, KY 40205, USA \\ ${ }^{2}$ Homes of Hope India-US \\ *Corresponding author: Annsley Frazier Thornton School of Education, Bellarmine University, 2001 Newburg Road, \\ Louisville, KY 40205, USAＴel: 1-502-272-8153Ｅ-mail: dpaige@bellarmine.edu
}

Received: December 12, $2012 \quad$ Accepted: February 4, $2013 \quad$ Online Published: April 7, 2013

doi:10.5430/wje.v3n2p11

URL: http://dx.doi.org/10.5430/wje.v3n2p11

This research is supported by Homes of Hope India-US, a registered 501c3.

\begin{abstract}
This study investigates the literacy skills of 193 students across grades three, five, seven, and nine in one private English medium school in Kerala, India. Students were assessed on their ability to read phonologically regular and irregular words, fluency with grade-level text, vocabulary knowledge, and comprehension skill. Results showed that students across all grade levels possessed the ability to apply phonological decoding skills that were equivalent to the 80th percentile for native English speakers while sightword recognition skills were commensurate with the 58th percentile. Oral reading fluency skills were assessed using grade-level narrative passages and average attainment ranged between the 50th and 70th percentiles. Vocabulary knowledge was found to decline consistently from 3rd through 9th grade, with percentiles dropping from the 25th to 8th percentile respectively. Text comprehension was similarly low with attainment averaging at the 16th percentile for all four grades. Implications for instruction are discussed.
\end{abstract}

Keywords: literacy; India; fluency; vocabulary; comprehension; ELL; ESL

\section{Introduction}

In 1951 India was a largely illiterate country with just $18 \%$ of the population possessing the most basic reading skills (Govinda \& Biswal, 2005). However, since gaining independence the development of a literate population has been a national goal resulting inthe implementation of multiple initiatives within a series of five-year-plans developed by the Government of India. One such initiative has been the National Adult Education Programme (NAEP). Founded in 1978, the NAEP set the foundation for the notion that a literate populace was in actuality a matter of socio-economic development. The objective of the NAEP was to turn 100 million illiterate people ages 15-35 into readers in just five years. As of 1988 it is estimated that 44.2 million people have been enrolled in the program and that about 45\% have attained literacy skills. In 1986 the National Policy on Education used the results of an evaluation study of the NAEP initiative as the basis of a recommendation that a National Literacy Mission (NLM) be created to implement and manage large-scale literacy programs in an attempt to create a literate population. As India transitions into a country where the majority of its population is considered to be literate, it would be helpful to determine what literate means in more technical terms. Indeed, as Indian students acquire the academic skills that are meant to ultimately prepare them for jobs within the national and global economic market, a more precise understanding of the literacy skillset that is being acquired is both informative and perhaps vital to ensuring that these students are properly prepared.To further such an understanding of literacy acquisition, this study measures the acquisition of reading skills by students in one private, English-medium school in southern India.

\subsection{Measuring Literacy in India}

The goal of a literate India involves determining what constitutes literacy and then measuring the percentage of the population who meet the criteria. In other words, when they are queried in a survey or interview, individuals 
self-identify as being literate. Such an undertaking is problematic not only in India, but also around the world as there is no accepted international definition of literacy (Puryear, 1995). In India this has led to a literacy definition that is defined by the individual organization gathering the estimate. For example, the Census of India (2001) uses what is called the standard Census Method (CM) that defines as literate a person who can read and write with understanding in any language. The method for determining who meets this standard is based upon self-identification where individuals simply declare themselves as literate or non-literate when queried by a census worker. The problem with this method is at least two-fold. First, it implies a view of literacy as a dichotomous skill that one either does, or does not, possess. In actuality literacy is more accurately viewed as a continuum of decoding and comprehension skills that are acquired by individuals to various levels of proficiency (Hoover \& Gough, 1990). The second obvious problem is that everyone is free to declare their possession of literacy skills without regard for verification, leading to the potential for an exaggerated rate as people declare the more socially accepted response of literate. A second, less often used method for determining literacy in India is the Reading Method (RM) where an individual is provided a Grade 2 text to read aloud to an evaluator who determines the reader's facility with the text. This method is based upon an actual demonstration of reading skill and as such, provides a standard based upon some degree of assessment. Here again though, the reading demonstration must be judged by an individual as adequate or not, the interpretation of which may be open to considerable disparity between raters. Finally, possessing the ability to read aloud a second grade text reflects a minimum degree of literacy skill that is inadequate for full participation in today's global economy (Friedman, 2006).

\subsection{The Gender Gap}

The Census of India (2011) recently found the national literacy rate to be $74 \%$, an increase of $8.7 \%$ over 2001 , with $82 \%$ of males and $65 \%$ of females determined to be literate. The gender discrepancy in literacy achievement reflects a long-standing male bias within the culture of India (Patkar, 1995; Sundaram \& Vanneman, 2008), although evidence exists that this gap is narrowing (Bloom, 2006; EFA Global Monitoring Report 2012). Additionally, the literacy achievement rate is not consistent across India as it varies from a low of $64 \%$ in the state of Bihar to a high of approximately $95 \%$ in Kerala. While the increase in literacy is good news for India, there is still little insight into the actual skills that literate Indians possess. Compounding the problem is the significant variance between Indian states in the percentage of children who are educated through the secondary level (EFA Global Monitoring Report 2012). For example, in West Bengal only $50 \%$ of adolescents attend or graduate from lower secondary schools while in Kerala graduation is close to $100 \%$. Here again, the gender gap varies across the country and is highest in Rajastan with about 30\% more males than females attending lower secondary school. This is in contrast to Kerala where close to $95 \%$ of students attend lower secondary school and where the gender gap in attendance is less than $5 \%$. When compared to other countries, the inter-state matriculation rate from lower to upper secondary education of approximately $60 \%$ places India in the poor category (EFA Global Monitoring Report 2012). Also of concern on a national scale is the fact that the adult literacy rate lags behind that of China by some $30 \%$, although at $22 \%$, the youth discrepancy rate is closing (Kingdon, 2007).

\subsection{The Goal for Learning}

While significant gender gaps persist in educational attendance and literacy achievement between Indian states, a question of national importance considers the desired learning outcomes as a result of school attendance. In this regard, Hanuschek and Woesman (2008) argue that merely attending school is insufficient for economic advancement. Rather, the most important outcome of education is the degree to which high-level cognitive skills such as literacy and math are acquired. Recent business literature in India has identified the difficulty in finding Indian employees who possess the necessary cognitive skills and suggests that education is inadequate to serve the needs of industry ("A Billion Brains," 2012). The recent economic growth of India has created a demand by Indian firms conducting business outside of the country where English is the lingua franca (Murthy, 2009). An example of this is that prior to the current global recession, India was the leading country for offshore outsourcing, accounting for some $\$ 47$ billion in annual revenue due primarily to its availability of English-speaking workers (Sourcing Line, 2012). For these reasons it is important to determine the extent to which students are becoming literate in English. Still another important outcome of education is the link to higher self-esteem that has been found in Indian children who are still attending school at age 12 compared to peers who are not (Rolleston \& James, 2012). Self-esteem is important as it provides students with the confidence and self-efficacy to pursue education and the acquisition of high-level cognitive skills (Wigfield\& Eccles, 2000).

\subsection{Theoretical Framework for Building Literacy Skills}

The goal of this study is describe the English literacy skills of Indian students attending a private, English medium 
school in Kerala. The theoretical framework for this study is based upon the simple view of reading that partitions reading into two domains composed of decoding and comprehension (Hoover \& Gough, 1990). Within this lens reading is viewed as decontextualized behavior consisting of decoding skills (reading words and phrases accurately and fluently) and cognitive processing capabilities which among others, includes the application of background knowledge, inference making, and metacognition in reading (August, Francis, Hsu, \& Snow, 2006; Linan-Thompson, Vaughn, Hickman-Davis, \& Kouzekanani, 2003). Also important in understanding text is the extent to which the reader understands vocabulary employed by the author (Baumann, 2009; Beck, Perfetti, \& McKeown, 1982; Biemiller \& Boote, 2006; Paige, Rasinski, \& Magpuri-Lavell, 2012a) as it is generally agreed that the purpose of developing the skills necessary to decode written text is to create an understanding of the author's message (Fox \& Alexander, 2009; Paige, 2012). While multiple factors interact to create comprehension (Hoffman, 2009), we take the view that assessing the efficiency with which a reader can apply the principles of the phonological code is reflected in a reader's automaticity with words and their overall reading fluency (Fuchs, Fuchs, Hosp, \& Jenkins, 2001; LaBerge \& Samuels, 1974; Paige, 2011; Torgesen, 1999). The ability to apply decoding principles has been found to be highly predictive of both reading fluency and comprehension (Paige, 2011; Torgesen, Wagner, Rashotte, Burgess, \& Hecht, 1997). It has been long established that phonological awareness coupled with reading practice leads to automaticity at the word and phrase level which allows the reader to focus on text comprehension (LaBerge \& Samuels, 1974; McCormick \& Samuels, 1979; Perfetti \& Hogaboam, 1975). While fluency with text is a necessary condition for full comprehension, it is not altogether sufficient for adequate reading comprehension (Rasinski, Reutzel, Chard, \& Linan-Thompson, 2011). This suggests that while disfluent readers may not comprehend some of what they read, students who are fluent readers are more likely to read with adequate comprehension.

\subsection{Vocabulary and Reading}

Children who have yet to learn to read depend almost exclusively on listening skills to build knowledge of vocabulary, while for older children it is wide reading that builds word knowledge (Anderson \& Freebody, 1981; Critchley, 1998; Seifert \& Espin, 2012). For this reason a large vocabulary is not necessary for very early reading comprehension in native speakers, however, vocabulary becomes a strong predictor of comprehension as more advanced texts contain a wide range of words that are outside the child's early speaking vocabulary (Becker, 1977; Storch \& Whitehurst, 2002). As such, to understand third- and fourth-grade books vocabulary knowledge possessed by average 9 and 10 year olds is a necessity (Chall, Jacobs, and Baldwin 1991; Chall \& Conrad, 1991). For children who possess limited vocabularies, this makes comprehension very difficult and makes the vocabulary gap that has been identified by other authors as beginning in the very first years evident in reading (Biemiller, 2010; Hart \& Risley, 1995, 2003). For the vast majority of children in India who are learning English as a second language, vocabulary acquisition is a critical component to effective reading comprehension.Vocabulary knowledge is best thought of as possessing word knowledge that is along a continuum, reflecting the idea that words often have more than one meaning and that knowledge of words is best developed through wide, independent reading (Adams, 1990; Cunningham, Perry, Stanovich, \& Share, 2002; Cunningham\& Stanovich, 1997, 1998; Nagy, Herman, \& Anderson, 1985; Nation, 2001). A large amount of independent reading outside of the school day is necessary for vocabulary development as readers tend to learn only about $15 \%$ of unknown words encountered in a text (Swanborn \& de Glopper, 1999). Vocabulary knowledge has been found to contribute in both direct and indirect ways to reading comprehension (Paige et al., 2012a, Paige et al., 2012b; Nagy, 2005). One example of an indirect route is the contribution that morphological awareness, or knowledge of the structure and form of words, makes to comprehension (Nagy et al., 2006). For example, if one knows the meaning of geology by understanding that geo refers to the earth, then other words such as geological, geographic, and geocentric are more easily understood.

\section{Problem Statement}

To gain a deeper understanding of English literacy skills in Indian children, 193 students across grades three, five, seven, and nine attending a private, English medium school, were administered literacy assessments measuring attainment of specific skills necessary for reading. This study seeks to answer the following research questions:

1) To what extent do students possess phonics knowledge and reading fluency when reading English text?

2) What is the breadth of English vocabulary knowledge possessed by students and how well do they comprehend when reading an English text?

3) Of the measured variables, which one(s) predicts reading comprehension? 


\subsection{Participants}

This study of 193 students attending grades (called standards in India) 3, 5, 7, and 9 was conducted in a private, religious-affiliated English medium school in the state of Kerala. Approximately 1,500 children attend the study school from pre-kindergarten through grade 12 (referred to as plus 2 in India). Virtually all students attending the school are English language learners as are all faculty members. Children attending the study school come from a variety of socio-economic status (SES) backgrounds. The best available indicator of the familial SES in the study school is the ability of parents to pay private school tuition. With an average household income reported to be Rs 63,000 (approximately US \$1189), the people of Kerala appear poor by U.S. standards and by even some Indian standards. However, when transfer payments from relatives employed outside India are considered, Kerala ranks first in household income among Indian states (Business Standard, 2010).To gain a sense of the SES of students attending the study school, school administrators reported to the study authors that approximately sixty percent of parents pay full tuition, about twenty percent pay some tuition, and approximately twenty percent of parents pay a very small fraction of the total tuition. As the mission of the school is to educate the poor, these students attend with little expectation of tuition payment by the school administration.

One objective of the study is to measure a cross-section of students so as to identify the developmental literacy trajectory of students across grades. School administration reported to the study authors that by grade three, the large majority of students possess reading skills. Considering this, it was decided that the student sample for assessment would begin with grade three (third standard) and continue through grades five, seven, and nine. Participant selection from the four grades involved a non-random quota sample so as to obtain an approximately equal number of participants across grades. In order to insure a distribution of students representing a cross-section of reading abilities, school administrators identified high, average, and low performing students so that the participant sample consisted of approximately twenty percent of children who were considered the best students, sixty percent of students whose academic attainment was considered average, and twenty percent who were considered to be struggling students. This resulted in a sample consisting of 47, 45, 46, and 55 students enrolled in grades three, five, seven, and nine respectively for a total sample of 193 students. Average age (standard deviation) for students at time of the assessment equaled 7.8(1.04) for grade three, 9.9(.58) for grade five, 11.7(.46) or grade seven, and 13.7(.53) for grade nine. Gender distribution across the assessed population consisted of 96 males (49.7\%) and 97 females $(50.3 \%)$.

\subsection{Assessments}

2.2.1 Word reading fluency: To measure student ability to decode words, all students were administered Form A of the Test of Word Reading Efficiency - 2 ([TOWRE] Torgesen, J., Wagner, R., \& Rashotte, C., 2012). The TOWRE uses two subtests to measure two skills that are critical to becoming a proficient reader. The sightword efficiency subtest (SWE) measures a student's ability to quickly recognize common words without the use of decoding strategies. The phonological decoding efficiency (PDE) subtest measures the accuracy and speed with which a student can apply phonological decoding principles to read pseudo-words that are phonologically regular. As a summative measure, the TOWRE combines the sightword reading and phonological decoding efficiency sub-scores into one overall measure called Total Word Reading Efficiency Score (TWRES). To complete the PDE subtest, students are given 45 seconds to read from a list of increasingly difficult, but phonetically irregular nonwords. For the SWE, students read as many words as possible in 45 seconds from a list of phonetically regular words. The test authors report that Form A of the SWE has a test-retest reliability of between .91 and .95 . Reliability for Form A of the PDE for the age group studied ranges between .91 and .95. The PDE and SWE form a Total Word Reading Efficiency scale which is reported by the test authors as a standard score. The TOWRE is based on a distribution with a mean of 100 and a standard deviation of 15.

2.2.2 Passage reading fluency: To assess the ability to read connected text aloud, all students were administered a grade-level narrative passage. In order to ensure that passages reflected grade-level reading, the Coh-Metrix on-line tool (Graesser et al., 2004) was utilized to determine readability as reflected by the Flesch-Kincaid scale (Flesh, 1951).To assess passage reading fluency, each student was presented with the passage and asked to read the story aloud. Students were timed individually for one minute while reading, during which any reading miscues or mispronunciations were noted by the test administrator. The measure of Rate indicates the total number of words attempted by the student whether read correctly or not. Miscues are any words that are pronounced incorrectly, omitted, or substituted by the reader. Words that are mispronounced but then self-corrected by the reader are considered to be read correctly. At the end of one minute, the last word attempted by the reader is noted and the total number of miscues is summed. The measure of correct-words-read-per-minute (CWPM) is calculated by subtracting 
miscues from rate. For example, the Rate for a reader is found to be 96 words read in one minute with 4 miscues. The CWPM then equals $92(96-4=92)$. The measure of CWPM can then be compared to U.S. national norms (Hasbrouck \& Tindal, 2006) for students within the same grade to determine the extent to which they are fluent readers. An instructional goal for all students is to reach approximately the $50^{\text {th }}$ percentile which would indicate typical oral reading fluency achievement.

2.2.3 Reading comprehension: The Test of Reading Comprehension-4 ([TORC-4] Brown, Wiederholt, \& Hammill, 2009) is a standardized comprehension assessment composed of five subtests. In the relational vocabulary subtest (RV) students are first given three related words as a prompt. From a list of four words, students then circle the two that are related in some way to three stimulus words. In the sentence completion subtest (SC), students read a sentence that is missing two words and then select a word pair that best fits the sentence. For the paragraph construction (PC) subtest students arrange a list of sentences into a logical temporal order. Text comprehension (TC) requires students to read a short passage and then answer a set of five multiple-choice questions about the passage. For the contextual fluency subtest (CF) students have three-minutes to identify individual words that are arranged next to each other in sentences without spaces or punctuation. Overall reading comprehension for the TORC-4 is reported as a reading comprehension index (RCI) and is computed with a mean of 100 and a standard deviation of 15 . The five subtests of the TORC are computed with a mean of 10 and a standard deviation of 3 . The TORC-4 subtest coefficients reported by the test authors for the assessed age-group range from .90 to .98 with test-retest reliabilities ranging from .82 to .95 .

\subsection{Assessment Administration}

The reading comprehension test was group-administered by the researchers to each grade of students, one grade at a time. Students were individually administered the TOWRE and the grade level narrative fluency passage in a quiet space inside the school library.

\section{Results}

Means and standard deviations for the measured variables are shown below in Table 1 while correlations are shown in Table 2. It should be noted that all percentile rankings are based on assessment instruments that were developed using native, English speaking students in the United States. Student knowledge of decoding principles as assessed by the PDE subtest of the TOWRE resulted in a mean standard score of 113.7, indicting achievement that is equal to the 80th percentile. While slightly lower, the sightword decoding mean score was found to equal 103.1, ranking at the 58th percentile. Proficiency with oral reading fluency was measured in terms of correct-words-per-minute (CWPM). For third-grade, CWPM equaled 73.5 (50th percentile) for fifth-grade, 130.4 (70th percentile) for seventh-grade, 152.4 (75th percentile), and for ninth-grade CWPM equaled 161.2 (70th percentile). Results from the TORC-4 suggest that student comprehension of text (RCI) remains fairly consistent across grades with 3rd, 7th, and 9th graders scoring at approximately the 18th percentile and 5th graders at the 12th. Analysis of the five subtests for the TORC show first, that vocabulary knowledge (RV) decreases as students progress through each grade with $3^{\text {rd }}$ grade attaining at the 25th percentile, 5th grade at the 13th, 7 th grade at the 11th, and 9th grade at the 8th percentile. Knowledge of sentence construction (SC) varies by grade with 3rd graders ranking at the 16th percentile, 5th graders at the $9^{\text {th }}$ percentile, and 7 th and 9 th graders at the $23^{\text {rd }}$ percentile. For the paragraph construction subtest (PC), large increases were found across grades with 3rd graders ranking at the 7th percentile, 5th graders at the 20th, 7th graders at the 35th, and 9th graders at the 46th percentile. Achievement on the subtest of text comprehension (TC) varied little across grades with attainment at the 3rd grade level equivalent to the 25th percentile, while the other three grades ranked at approximately the 35th percentile. The measure of contextual fluency (CF) revealed that 3rd, 5th, and 7th grade students achieved at the 27th percentile, while 9th graders ranked slightly lower at about the 23rd percentile. To make these trends between the decoding and comprehension variables more easily interpretable, Figure 1 displays several of them in graph form. The variables related to decoding are shown in light gray (PDE, fluency, and SWE) while comprehension related variables are shown in black (PC, RCI, and RV). The graph reveals two major ideas. First, students struggle with comprehension (RCI) and vocabulary (RV) across all four grades, however, they do improve greatly in their ability to understand story order (PC). Secondly, students quickly increase in their ability to automatically recognize sightwords and generally perform at high levels on decoding and reading fluency measures, particularly after the third grade. 
Table 1: Means and Standard Deviations of the Measured Variables by Gender and Grade

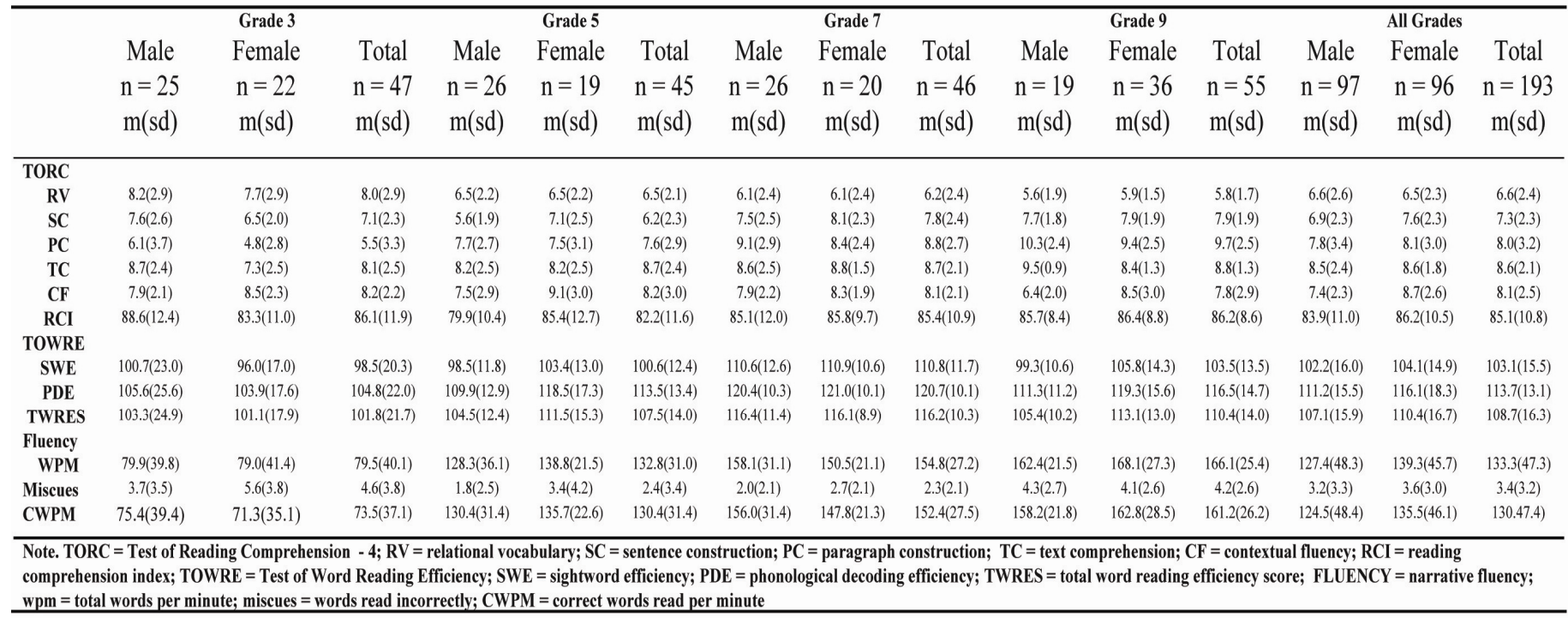

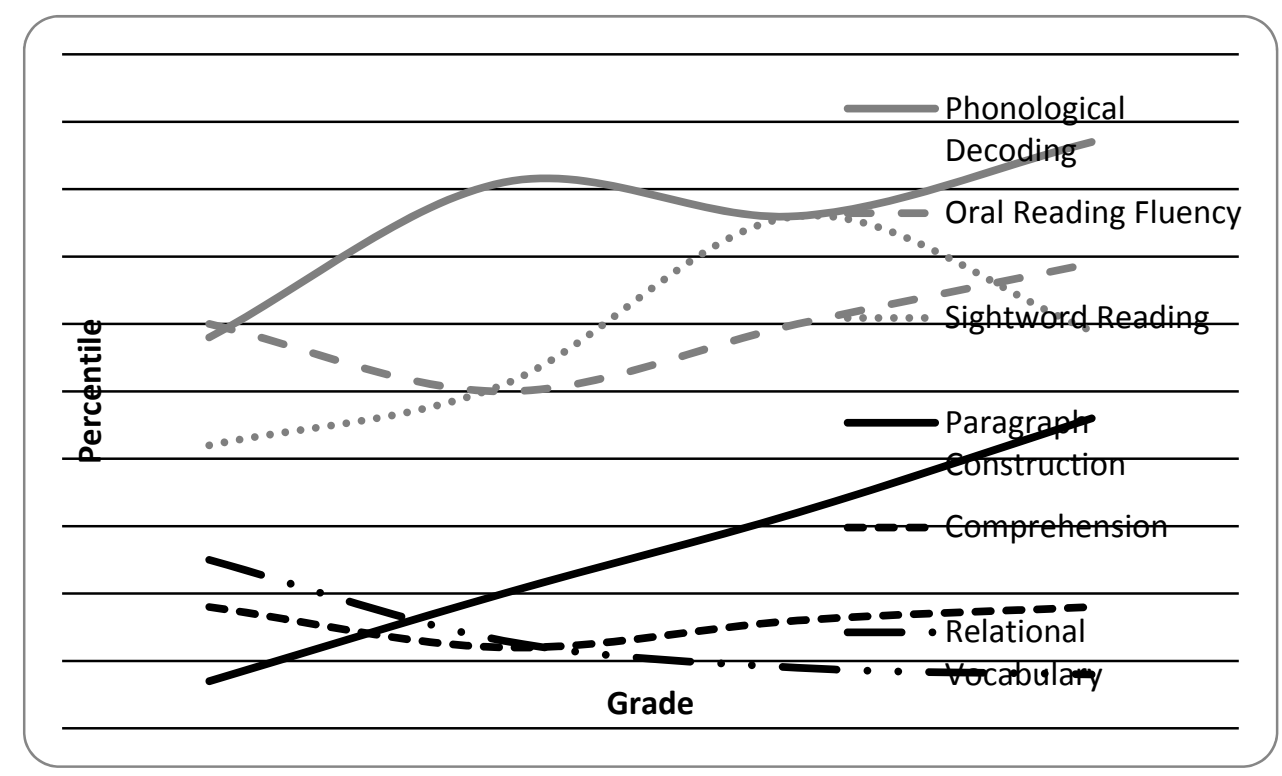

Figure 1: Between Grade Trend Line by Percentile for Phonological Decoding (PDE), Fluency, Sightword Decoding (SWE), Paragraph Construction (PC), Comprehension (RCI), and Vocabulary (RV) 
Table 2: Bivariate Correlations between the Measured Variables

\begin{tabular}{|c|c|c|c|c|c|c|c|c|c|c|c|}
\hline Variable & $\mathrm{RCI}$ & $\mathrm{RV}$ & $\mathrm{SC}$ & $\mathrm{PC}$ & $\mathrm{TC}$ & $\mathrm{CF}$ & SWE & PDE & WPM & Miscues & CWPM \\
\hline $\mathrm{RCI}$ & 1.00 & & & & & & & & & & \\
\hline RV & $.680 * *$ & 1.00 & & & & & & & & & \\
\hline $\mathrm{SC}$ & $.736^{* *}$ & $.384 * *$ & 1.00 & & & & & & & & \\
\hline $\mathrm{PC}$ & $.655^{* *}$ & $.184 *$ & $.478 * *$ & 1.00 & & & & & & & \\
\hline $\mathrm{TC}$ & $.652 * *$ & $.328 * *$ & $.457 * *$ & $.382 * *$ & 1.00 & & & & & & \\
\hline $\mathrm{CF}$ & $.450^{* *}$ & $.219 *$ & .103 & .101 & .090 & 1.00 & & & & & \\
\hline SWE & $.505^{* *}$ & $.328 * *$ & $.440 * *$ & $.380 * *$ & $.412 * *$ & $.171^{*}$ & 1.00 & & & & \\
\hline PDE & $.447 * *$ & $.260 * *$ & $.357^{* *}$ & $.418 * *$ & $.430 * *$ & .140 & $.826^{* *}$ & 1.00 & & & \\
\hline Rate & $.264 * *$ & -.090 & $.286 * *$ & $.555 * *$ & $.335 * *$ & .048 & $.586^{* *}$ & $.675^{* *}$ & 1.00 & & \\
\hline Miscues & $-.282 *$ & $-.151^{*}$ & $-.181 *$ & $-.307^{* *}$ & $-.211^{* *}$ & $-.157^{*}$ & $-.325^{* *}$ & $-.373 * *$ & $-.182 *$ & 1.00 & \\
\hline CWPM & $.283 * *$ & -.071 & $.296^{* *}$ & $.567 * *$ & $.348^{* *}$ & .060 & $.599 * *$ & $.692 * *$ & $.996^{* *}$ & $-.246 * *$ & 1.00 \\
\hline
\end{tabular}

Note. $\mathrm{RV}=$ relational vocabulary; $\mathrm{SC}=$ sentence construction; $\mathrm{PC}=$ paragraph construction; $\mathrm{TC}=$ text comprehension; $\mathrm{CF}=$ contextual

fluency; RCI = reading comprehension index; $\mathrm{SWE}=$ sightword efficiency; $\mathrm{PDE}=$ phonological decoding efficiency; Rate $=$ words per minute; Miscues $=$ reading deviations; $\mathrm{CWPM}=$ correct words per minute

$* p<.05 ; * * p<.01$

To determine if students differed by gender on any of the measured variables, an analysis of variance (ANOVA) was calculated for each of the three assessments (TOWRE, oral reading fluency, and the TORC) and their associated subtests. A Bonferroni adjustment was applied to the results to account for experimenter-wise error that can result in a false-positive (Field, 2009). Results found one statistically significant difference by gender on the measure of contextual fluency (CF) where females scored higher than males by just over one-half of a standard deviation, $F(1,191)=13.5, p<.001, d=.53$.

In reviewing relationships between variables, Hopkins' (2006) interpretation is used where a correlation (Pearson's $r$ ) below 0.1 is considered trivial, between 0.1 and 0.3 is small, larger than 0.3 but smaller than 0.5 is moderate, from 0.5 to less than 0.7 is large, from 0.7 to less than 0.9 is very large, and 0.9 or greater is nearly perfect. The first statistically significant relationship is between vocabulary and comprehension where a large relationship ( $r=.68)$ is found. Also rating as a large and significant relationship with reading comprehension are the other three subtests (SC, $\mathrm{PC}$, and TC) which form the reading comprehension index (RCI) of the TORC. Of significance is the importance of word reading to comprehension where sightword efficiency (SWE) shares a large relationship $(r=.51)$ with comprehension (RCI) while knowledge of decoding principles in the form of PDE shares a moderate $(r=.45)$ relationship with comprehension. Of note is the small and statistically significant relationship between fluency and reading comprehension (RCI) where Pearson' $r=.28$.

To gain insight into which measured variable(s) best predicts reading comprehension in the study sample, a hierarchical regression analysis was conducted. As suggested by Meyers, Well and Lorch (2010) variables were entered using a forward selection process by the strength of their correlation with reading comprehension, the criterion variable. Previous research has found that vocabulary, proficiency with word identification, phonics knowledge, and fluency are most often significant predictors of comprehension in native English speakers (Paige, 2011, Paige et al., 2012a). Before beginning, the data was evaluated and found to contain no multicollinearity between variables, no influential outliers, and no violations of homoscedasticity. Our initial analysis included all 193 students across the four grades. For our first model we regressed vocabulary, sightword efficiency (SWE), phonics knowledge (PDE), and fluency (CWPM) onto comprehension (RCI). An examination of the resulting beta coefficients revealed that phonics knowledge (PDE) was not a significant predictor of comprehension. The final model shown in Table 3 explains $57.7 \%$ of the variance in comprehension with vocabulary being the strongest predictor followed by sightword reading and then fluency. Standardized beta weights for the predictor variables equaled $.631, .217$, and .163 for vocabulary, sightword reading and fluency respectively. 
Table 3: Results of Hierarchical Regression Model Predicting Comprehension (RCI) for All Students

\begin{tabular}{lcccccc}
\hline & & & & & \\
& $\mathrm{B}$ & $S E B$ & $B$ & $R^{2}$ & $\Delta R^{2}$ \\
\hline Variable 1 & & & & & & \\
$\quad$ Constant & 65.25 & 1.65 & & & & \\
$\quad$ RV & 3.01 & .24 & .743 & .46 & & $12.81^{* * *}$ \\
Variable 2 & & & & & & \\
$\quad$ Constant & 45.60 & 3.56 & & & & $11.03^{* * *}$ \\
& 2.53 & .23 & .57 & .46 & & \\
Vocabulary & & & & & & \\
$\quad$ Sightword & .22 & .04 & .32 & .55 & .09 & \\
Variable 3 & & & & & & \\
$\quad$ Constant & 48.21 & 3.55 & & & & \\
& 2.79 & .24 & .63 & .46 & & $11.84^{* * * *}$ \\
Vocabulary & & & & & & \\
$\quad$ Sightword & .11 & .05 & .16 & .55 & .09 & $2.44^{*}$ \\
$\quad$ Fluency & .05 & .02 & .22 & .58 & .03 & $3.44^{* *}$ \\
\hline
\end{tabular}

Note. Vocabulary $=\mathrm{RV}$; Sightword $=$ SWE; Fluency $=$ CWPM.

$* * * p<.001 ; * * p<.01 ; * p<.05$.

Our next analysis (Table 4) sought to determine which variable(s) best predict reading comprehension (RCI) by grade level with results shown in Table 4. For the third and fifth grade levels, the correlations between variables exhibited the same order of relationship with comprehension (RV, PDE, SWE, and CWPM), however for both the seventh- and ninth-grade samples, the order became RV, SWE, CWPM, and PDE. For third- and fifth-grade, vocabulary was the sole significant predictor of comprehension accounting for $72 \%$ and $43.5 \%$ of the variance in RCI respectively. In the seventh- and ninth-grade models, vocabulary was again the sole significant predictor of reading comprehension accounting respectively for $51 \%$ and $39 \%$ of total comprehension variance.

Table 4: Results of Hierarchical Regression Model Predicting Comprehension (RCI) by Grade

\begin{tabular}{|c|c|c|c|c|c|}
\hline & B & $S E B$ & $B$ & $R^{2}$ & $t$ \\
\hline \multicolumn{6}{|l|}{ Third Grade } \\
\hline Constant & 58.35 & 2.75 & & & \\
\hline Vocabulary & 3.46 & .32 & .85 & .71 & $10.75^{* * *}$ \\
\hline \multicolumn{6}{|l|}{ Fifth Grade } \\
\hline Constant & 59.00 & 4.24 & & & \\
\hline Vocabulary & 3.58 & .62 & .66 & .44 & $5.75^{* * *}$ \\
\hline \multicolumn{6}{|l|}{ Seventh Grade } \\
\hline Constant & 65.28 & 3.17 & & & \\
\hline Vocabulary & 3.27 & .48 & .72 & .51 & $6.79 * * *$ \\
\hline \multicolumn{6}{|l|}{ Ninth Grade } \\
\hline Constant & 67.55 & 3.37 & & & \\
\hline Vocabulary & 3.21 & .56 & .62 & .39 & $3.44 * * *$ \\
\hline $\begin{array}{l}\text { Note. Vocabulary } \\
* * * p<.001 .\end{array}$ & al voca & & & & \\
\hline
\end{tabular}

\section{Discussion}

Results of the present study found that regardless of grade level, the assessed population of 193 students exhibited phonics knowledge that averaged at the 80th percentile while sightword recognition skills were found to be commensurate with the 58th percentile for similarly aged native English speakers. Additionally, oral reading fluency skills for the third-grade sample equaled the 50th percentile while students in the fifth-, seventh-, and ninth-grade samples achieved at the 70th percentile. The reader should keep in mind that students attending the study school 
come from homes where Malayalam is the native language and where English is seldom spoken. These results suggest that in this particular English medium school, students have developed phonics knowledge and reading fluency skills to a very high level not seen in many U.S. schools (Lee, 2010; Paige, 2011; Paige \& Magpuri-Lavell, 2011; Rasinski et al., 2005; Teale, 2009). While research suggests that English language learners (ELLs) often reach word reading skill levels that are commensurate with native language learners, the present study results suggest that this group of readers significantly exceeds the level typified by average attainment at the 50th percentile (Lesaux \& Geva, 2006; Lesaux, Rupp, \& Siegel, 2007). These results suggest that English language learners can be taught to decode and fluently read English text to a very high level in a context where the teachers are themselves, English language learners and where no English is spoken at home.

Assessment results reflecting student facility with vocabulary and comprehension were quite different than those for word knowledge and reading fluency. Results from the linear regression analysis showed clearly that vocabulary knowledge was the sole predictor of reading comprehension. One reason for this result may be that all students had mastered decoding and fluent reading to a high level, leaving little variance within the participant sample which might otherwise have shown reading fluency to also be a significant predictor of reading comprehension. Student vocabulary knowledge for all grade levels was found to average at the 13th percentile. Additionally, vocabulary attainment decreased across grade level. While third-grade students attained at the 25 th percentile, fifth, seventh, and ninth-grade vocabulary scores consistently declined (13th, 11th, and 8th respectively) suggesting that students were failing to acquire an amount of new vocabulary knowledge necessary to maintain achievement at just the 25th percentile. Comprehension was also very low with average attainment across grades remaining fairly consistent at the 16th percentile. Results did reveal that student knowledge of story construction increased strongly from third- to ninth-grade, beginning at the $7^{\text {th }}$ percentile for third-graders and rising to the 46th percentile for ninth-graders. This finding is also commensurate with other studies that have found vocabulary and comprehension attainment to lag that of native language learners (Lesaux, 2006; Shanahan \& Beck, 2006; Proctor, August, Carlo, \& Snow, 2005).

One finding of particular interest is the relative decline in vocabulary attainment across grades. Several studies suggest that increasing vocabulary knowledge is necessary for improving text comprehension (August, Francis, Hsu, \& Snow, 2006; Linan-Thompson, et al., 2003; Mathes et al., 2005). The declining percentiles suggest that students require greatly increased exposure to vocabulary. Gersten and Baker (2000) recommend that effective instruction for ELLs should use vocabulary as a foundation for the curriculum and that both peer-tutoring and cooperative learning strategies should be used to facilitate vocabulary learning. But what conditions must be in place to help students increase their vocabulary knowledge? Nation (2001) suggests three necessary conditions. First, students must notice words. Secondly, words must then be frequently retrieved by the student while third, the student must engage in generative use of the word. Noticing a word means directing one's attention to the word and becoming aware that it is a useful item in language (Ellis, 1991; Schmidt, 1990). For a word to be noticed by a student, it may be explicitly called to the student's attention by a teacher. The student may also realize that the word is salient within the text and that knowledge of the word fills in their knowledge of the language. Retrieval, the second condition for increasing vocabulary knowledge, means that the word can be subsequently recalled from memory on demand (Baddeley, 1986). Baddeley suggests that each retrieval of the word from memory, whether it is receptive (listening or reading) or productive (speaking or writing) retrieval, strengthens subsequent retrieval attempts. In their theory of automaticity, LaBerge and Samuels (1974) also hypothesize that word retrieval strengthens subsequent attempts to retrieve the word. For example, Kalia and Reese (2009) found that receptive vocabulary skills in Indian children was moderated by the amount of time that parents spent reading English books at home, thus exposing their children to a wider range of English vocabulary and providing them opportunities for receptive retrieval. Key to improvement in word retrieval is the opportunity for repetition of the vocabulary item to be learned. For repetition to be successful it should be distributed over a period of time rather than massed in short bursts, meaning that giving repeated attention to a word over several days is better than the same number of repetitions in just a few minutes (Bloom \& Shuell, 1981; Dempster, 1987). The third condition for remembering a word involves generative processing which occurs when the learner subsequently uses the word in a way that is different from that which occurred when first learning the word (Nation, 2001). This condition reflects the notion that vocabulary knowledge involves a continuum of meaning and that as student knowledge of the word deepens, the continuum broadens. Stahl and Vance (1986) suggest that the use of oral language skills in the form of group discussion is important in aiding students in expanding their vocabulary knowledge. 


\section{Conclusion}

Using a decontextualized view of reading framed by the simple view of reading (Hoover \& Gough, 1990), this descriptive study provides a clear picture of the reading skills of 193 Indian students, all of whom are English language learners attending grades 3, 5, 7, and 9 in one English medium school within the state of Kerala. While all teachers in the study school are themselves ELLs, all students learned decoding and fluency skills to a very high level. What was also revealed was that students possessed very limited English vocabularies which greatly restrained reading comprehension. Vocabulary knowledge was found to be the sole predictor of comprehension. As such, this study provides a glimpse into literacy achievement in one Indian English medium school and specifically defines in measurable terms the literacy skills of a cross-section of students. As this study is confined to one school, what is not known is the extent to which English literacy skills are being acquired across all schools purporting to provide instruction in English in India. None the less, this study provides documentation of what can be accomplished in one English medium school, as well as a view of the challenges of English literacy acquisition in a state where almost all students are English language learners. For students to eventually matriculate to positions of employment within the global economy, success with English literacy is critical and this study contributes to the knowledge base of how that challenge is being answered within a single school.

\section{References}

A billion brains. (2012, October).The Economist, 404(8804), S10-S12.

Adams, M. J. (1990). Beginning to read: Thinking and learning about print. Cambridge, MA: MIT Press.

Anderson, R. C., \& Freebody, P. (1981). Vocabulary knowledge. In J. Guthrie (Ed.), Comprehension and teaching: Research reviews (pp. 77-117). Newark, DE: International Reading Association.

August, D., Francis, D. J., Hsu, H. A., \& Snow, C. E. (2006). Assessing reading comprehension in bilinguals. The Elementary School Journal, 107(2), 221-248. http://dx.doi.org/ 10.101086/510656

Baddeley, A.D. (1986). Working memory. Oxford: Clarendon Press.

Baumann, J. F. (2009). Vocabulary and reading comprehension. In S. E. Israel and G. G. Duffy (Eds.), Handbook of research on reading comprehension (pp. 323-346). New York, NY: Routledge.

Beck. I.L., Perfetti, C.A., \& McKeown, M.G. (1982). The effects of long-term vocabulary instruction on lexical access and reading comprehension. Journal of Educational Psychology, 74(4), 506-521. http://dx.doi.org/10.1037/0022-0663.74.4.506

Becker, W. C. (1977). Teaching reading and language to the disadvantaged - What we have learned from field research. Harvard Educational Review, 47, 518-543.

Biemiller, A., \& Boote, C. (2006). An effective method for building meaning vocabulary in primary grades. Journal of Educational Psychology, 98(1), 44-62. http://dx.doi.org/10.1037/0022-0663.98.1.44

Bloom, D. E. (2006). Measuring global educational progress. Cambridge, MA: American Academy of Arts and Sciences.

Bloom, K. C., \& Shuell, T. J. (1981). Effects of massed and distributed practice on the learning and retention of second-language vocabulary. Journal of Educational Research, 74(4), 245-248.

Business Standard (2010). Per capita income: Kerala is actually no. 1. June 28, 2010.

Census of India (2001).State of Literacy (Chapter 7). Provisional Population Totals, Series 1, India, Paper 1 of 2001.

Census of India (2011). State of Literacy (Chapter 6).

Chall, J. S., \& Conrad, S. S. (1991). Should textbooks challenge students? New York, NY: Teachers College Press.

Chall, J. S., Jacobs, V., \& Baldwin, L. (1990). The reading crisis: Why poor children fall behind. Cambridge, MA: Harvard University Press.

Critchley, M. P. (1998). Reading to learn: Pedagogical implications of vocabulary research. The Language Teacher, 22(9), 10-13.

Cunningham, A.E., \& Stanovich, K.E. (1997). Early reading acquisition and its relation to reading experience and ability 10 years later. Developmental Psychology, 33(6), 934-945. http://dx.doi.org/10.1037/0012-1649.33.6.934

Cunningham, A.E., \& Stanovich, K.E. (1998). What reading does for the mind. American Educator, 22(1-2), 8-15. 
Cunningham, K. E., Perry, K. E., Stanovich, K. E., \& Share, D. L. (2002). Orthographic learning during reading: Examining the role of self-teaching. Journal of Experimental Child Psychology, 82(3), 185-199. http://dx.doi.org/10.1016/S0022-0965(02)00008-5

Dempster, F. N. (1987). Effect of variable encoding and spaced presentation on vocabulary learning. Journal of Educational Psychology, 79(2), 162-170.

EFA Global Monitoring Report 2012: Youth and skills: Putting education to work. Paris: United Nations Educational, Scientific and Cultural Organization.

Ellis, R. (1991). The interaction hypothesis: A critical evaluation. In E. Sadtono (Ed.), Language Acquisition and the Second/Foreign Language Classroom (pp. 179-211). RELC Anthology: Series 28.

Field, A. (2009). Discovering statistics using SPSS(3rd ed.). London: Sage.

Flesch, R. F. (1951). How to test readability. New York: Harper.

Fox, E., \& Alexander, P. A. (2009). Text comprehension: A retrospective, perspective, and prospective. In S. E. Israel \& G. G. Duffy (Eds.), Handbook of research on reading comprehension (pp. 227-239). New York: Routledge.

Friedman, T. L. (2006). The world is flat. London: Penguin Books.

Fuchs, L. S., Fuchs, D., \& Hosp, M, K., \& Jenkins, J. R. (2001). Oral reading fluency as an indicator of reading competence: A theoretical, empirical, and historical analysis. Scientific Studies of Reading, 5(3), 239-256. http://dx.doi.org/10.1207/S1532799XSSR0503_3

Gersten, R., \& Baker, S. (2000). What we know about effective instructional practices for English-language learners. Exceptional Children, 66, 454-470.

Govinda, R., \& Biswal, K. (2005). Mapping literacy in India: Who are the illiterates and where do we find them? Paper commissioned for the EFA Global Monitoring Report 2006, Literacy for Life. Retrieved from http://unesdoc.unesco.org/images/0014/001460/146016e.pdf

Graesser, A., McNamara, D.S., Louwerse, M., \& Cai, Z. (2004). Coh-Metrix: Analysis of text on cohesion and language. Behavioral Research Methods, Instruments, and Computers, 36, 193-202. http://dx.doi.org/10.3758/BF03195564

Hanuschek, E. A., \& Woessman, L. (2008). The role of cognitive skills in educational development. Journal of Economic Literature, 46(3), 607-668. http://dx.doi.org/10.1257/jel.46.3.607

Hart, B., \& Risley, T. R. (1995). Meaningful differences in the everyday experience of young American children. Brooks: Baltimore.

Hart, B., \& Risley, T. R. (2003). The early catastrophe: The 30 million word gap by age 3. American Educator, 27(1), 4-9.

Hasbrouck, J., \& Tindal, G. A. (2006). Oral reading fluency norms: A valuable assessment tool for reading teachers. The Reading Teacher, 59(7), 636-644. http://dx.doi.org/10.1598/RT.59.7.3

Hoffman, J. V. (2009). In search of the "Simple View" of reading comprehension. In S. E. Israel \& G. G. Duffy (Eds.), Handbook of research on reading comprehension (pp. 54 - 66). New York: Routledge.

Hoover, W. A., \& Gough, P. B. (1990). The simple view of reading. Reading and Writing: An Interdisciplinary Journal, 2, 127-160. http://dx.doi.org/ 10.1007/BF00401799

Hopkins, W. G. (2006, June 19). A scale of magnitudes for the effect statistics. A new view of statistics. Retrieved from http://www.sportsci.org/resource/stats/effectmag.html

Kalia, V., \& Reese, E. (2009). Relations between India children's home literacy environment and their English oral language and literacy skills. Scientific Studies of Reading, 13(2), 122-145. http://dx.doi.org/10.1080/10888430902769517

Kingdon, G. G. (2007). The progress of school education in India. Economic and Social Research Council, Global Poverty Research Group. Retrieved from economics.ouls.ox.ac.uk/12991/1/gprg-wps-071.pdf

LaBerge, D., \& Samuels, S. J. (1974). Toward a theory of automatic information processing in reading. Cognitive Psychology, 6, 293-323. http://dx.doi.org/10.1016/0010-0285(74)90015-2

Lee, J. (2010). Tripartite growth trajectories of reading and math achievement: Tracking national academic progress at primary, middle, and high school levels. American Educational Research Journal, 47(4), 200-232. 
http://dx.doi.org/10.3102/0002831210365009

Lesaux, N. K., \& Geva, E. (2006). Synthesis: Development of literacy in language-minority students. In D. August \& T. Shanahan (Eds.), Developing literacy in second-language learners: Report of the National Literacy Panel on Language-Minority Children and Youth (pp. 75-122). Mahwah, NJ: Erlbaum.

Lesaux, N. K., Rupp, A. A., \& Siegel, L. S. (2007). Growth in reading skills of children from diverse linguistic backgrounds: Findings from a 5-year longitudinal study. Journal of Educational Psychology, 99(4), 821- 834. http://dx.doi.org/10.1037/0022-0663.99.4.821

Linan-Thompson, S., Vaughn, S., Hickman-Davis, P., \& Kouzekanani, K. (2003). Effectiveness of supplemental reading instruction for second-grade English language learners with reading difficulties. The Elementary School Journal, 103(3), 221-238.

Mathes, P. B., Denton, C. A., Fletcher, J. M., Anthony, J. L., Francis, D. J., \& Schatschneider, C. (2005). An evaluation of two reading interventions derived from diverse models. Reading Research Quarterly, 40(2), 148-183. http://dx.doi.org/10.1598/RR Q40.2.2

McCormick, C., \& Samuels, S. J. (1979). Word recognition by second graders: The unit of perception and interrelationships among accuracy, latency, and comprehension. Journal of Reading Behaviour, 11, 107-108. http://dx.doi.org/10.1080/10862967909547314

Murthy, N. R. N. (2009). A Better India, a Better World. New Delhi, India: Penguin Group.

Myers, J. L., Well, A. D., \& Lorch, R. F. Jr. (2010). Research design and statistical analysis(3rd. ed.). New York: Routledge.

Nagy, W. E. (2005). Why vocabulary instruction needs to be long-term and comprehensive. In E. H. Hiebert \& M. L. Kamil (Eds.), Teaching and learning vocabulary: Bringing research to practice(pp. 27-44). Mahwah, NJ: Erlbaum.

Nagy, W. E., Herman, P., \& Anderson, R. C. (1985). Learning words from context. Reading Research Quarterly, 20(2), 223-253.

Nagy, W., Berninger, V. W., \& Abbott, R. D. (2006). Contributions of morphology beyond phonology to literacy outcomes of upper elementary and middle-school students. Journal of Educational Psychology, 98(1), 134-147. http://dx.doi.org/10.1037/0022-0663.98.1.134

Nation, I. S. P. (2001). Learning vocabulary in another language. Cambridge: Cambridge University Press.

Paige, D. D. (2011). Engaging struggling adolescent readers through situational interest: A model proposing the relationships among extrinsic motivation, oral reading fluency, comprehension, and academic achievement. Reading Psychology, 32(5), 395-425. http://dx.doi.org/10.1080/02702711.2010.495633

Paige, D. D. (2012). The importance of adolescent fluency. In T. Rasinski, K. Blackowicz, and C. Lems (Eds.), Fluency instruction: Research-based best practices. NY: Guilford.

Paige, D. D., \& Magpuri-Lavell, T. (2011). Unpacking adolescent literacy skills in a high-poverty, urban high school. In T. Morrison, L. Martin, M. Boggs, \& S. Szabo, (Eds.), Literacy promises: The thirty-third yearbook, a double peer reviewed publication of the Association of Literacy Educators and Researchers: Vol. 33 (pp. 219-236). Retrieved from www.aleronline.org/displaycommon.cfm?an=1\&subarticlenbr $=6$

Paige, D. D., Rasinski, T. V., \& Magpuri-Lavell, T. (2012a). Is fluent expressive reading important for high school readers? Journal of Adult and Adolescent Literacy, 56(1), 67-76. http://dx.doi.org/10.1080/02702711.2010.495633

Paige, D. D., Rasinski, T. V., \& Magpuri-Lavell, T. (2012b). Interpreting the relationships among prosody, automaticity, accuracy, and silent reading comprehension in secondary students. Manuscript submitted for publication.

Patkar, A. (1995). Socio-economic status and female literacy in India. International Journal of Educational Development, 15(4), 401-409. http://dx.doi.org/10.1016/0738-0593(95)00023-V

Perfetti, C. A., \& Hogaboam, T. (1975). The relationship between single word decoding and reading comprehension skill. Journal of Educational Psychology, 67, 461-469. http://dx.doi.org/10.1037/h0077013

Proctor, C. P., August, D., Carlo, M., \& Snow, C. (2005). Native Spanish-speaking children reading in English: Toward a model of comprehension. Journal of Educational Psychology, 97, 246-256. 
Puryear, J. M. (1995). International education statistics and research: Status and problems. International Journal of Educational Development, 15(1), 79-91.http://dx.doi.org/10.1016/0738-0593(94)E0015-G

Rasinski, T. V., Padak, N. D., McKeon, C. A., Wilfong, L. G., Friedauer, J. A., \& Heim, P. (2005). Is reading fluency a key for successful high school reading? Journal of Adolescent \& Adult Literacy, 49(1), 22-27. http://dx.doi.org/10.1598/JAAL.49.1.3

Rasinski, T. V., Reutzel, R., Chard, D., \& Linan-Thompson, S. (2011). Reading fluency. In M. L. Kamil, P. D. Pearson, E. B. Moje, \& P. Afflerbach (Eds.), Handbook of Reading Research (Vol. 4) pp. 286-319. Mahwah, NJ: Erlbaum.

Rolleston, C., \& James, Z. (2012). The role of schooling in skill development: Evidence from young lives in Ethiopia, India, Peru, and Vietnam. Background paper for EFA Global Monitoring Report 2012.

Schmidt, R. W. (1990). The role of consciousness in second language learning. Applied Linguistics, 11, 129-158. http://dx.doi.org/10.1093/applin/11.2.129

Seifert, K., \& Espin, C. (2012). Improving reading of science text for secondary students with learning disabilities: Effects of text reading, vocabulary learning, and combined instruction. Learning Disabilities Quarterly, 35(4), 236-247. http://dx.doi.org/10.1177/0731948712444275

Shanahan, T., \& Beck, I. L. (2006).Effective literacy teaching for English language learners.In D. August \& T. Shanahan (Eds.), Developing literacy in second-language learners: report of the National Literacy Panel on Language-Minority Children and Youth (pp. 415 - 488). Mahwah, NJ: Erlbaum.

Sourcing Line (2012). Global services and outsourcing locations. Retrieved from http://www.sourcingline.com/outsourcing-location/india

Stahl, S. A., \& Vance, S. J. (1986). Discussion is what makes semantic maps work in vocabulary instruction. The Reading Teacher, 40, 62-67.

Storch, S. A., \& Whitehurst, G. J. (2002). Oral language and code-related precursor to reading: Evidence from a longitudinal structural model. Developmental Psychology, $38(6), \quad 934-947$. http://dx.doi.org/10.1037/0012-1649.38.6.934

Sundaram, A., \& Vanneman, R. (2008). Gender differentials in literacy in India: The intriguing relationship with women's labor force participation. World Development, 36(1), 128-143. http://dx.doi.org/10.1016/j.worlddev.2007.02.017

Swanborn, M., \& de Glopper, K. (1999). Incidental word learning while reading: A meta-analysis. Review of Educational Research, 69(3), 261-285. http://dx.doi.org/10.3102/00346543069003261

Teale, W. H. (2009).Students learning English and their literacy instruction in urban schools. Reading Teacher, 62(8), 699-703. http://dx.doi.org/10.1598/RT.62.8.9

Torgesen, J. K. (1999). Phonologically based reading disabilities: toward a coherent theory of one kind of learning disability. In R. J. Sternberg \& L. Spear-Swerling (Eds.), Perspectives on learning disabilities (pp. 231-262). New Haven: Westview Press.

Torgesen, J. K., Wagner, R. K., \& Rashotte, C. A. (1999). Test of Word Reading Efficiency. Austin, TX: Pro-Ed.

Torgesen, J. K., Wagner, R. K., Rashotte, C. A., Burgess, S., \& Hecht, S. (1997). Contributions of phonological awareness and rapid automatic naming to the growth of word-reading skills in second- to fifth-grade children. Scientific Studies of Reading, 1(2), 161-185. http://dx.doi.org/10.1207/s1532799xssr0102_4

Wigfield, A., \& Eccles, J. S. (2000). Expectancy-value theory of achievement motivation. Contemporary Educational Psychology, 25, 68-81. http://dx.doi.org/10.1006/ceps.1999.1015 